Sharif University of Technology
Scientia Iranica
Transactions E: Industrial Engineering
http://scientiairanica.sharif.edu

\title{
Product substitution with customer segmentation under panic buying behavior
}

\author{
Y.-C. Tsao* and P.V.R.P. Raj \\ Department of Industrial Management, National Taiwan University of Science and Technology, Taipei, Taiwan.
}

Received 31 August 2017; received in revised form 2 December 2018; accepted 26 January 2019

KEYWORDS
Panic buying;
Customer satisfaction;
Customer
segmentation;
Substitution;
Mixed Integer
Program (MIP).

\section{Introduction}

Panic purchasing caused by interruption in supply occurs frequently in today's market. Higher oil prices and changes in government policies lead to disruptions in supply chain. For example, in the protest against Indian government's taxation policies when owners of fuel stations and petrol tankers announced an indefinite strike [1], Nepal Oil Corporation provided additional fuel in the Kathmandu Valley to calm down panicked buyers who were queuing in front of petrol stations, driven by the fear of impending shortages [2]. Further, natural disasters, strikes, and terrorist attacks can cause interruption in supply [3-5]. He et al. [6] stated that the management of interruption in supply was a

*. Corresponding author. Tel.: 886-2-27303624

E-mail address: yctsao@mail.ntust.edu.tw (Y.-C.Tsao) critical challenge for managers in the present globalized and highly uncertain business environment.

Panic buying often intensifies the supply-demand imbalance, thus negatively affecting high-indexed customers. Therefore, suppliers should first focus on satisfying high-indexed customers. Generally, wholesalers hold excess inventory to avoid shortages, thereby establishing a reliable relationship with retailers. However, this behavior can result in excess inventory in one product and shortage in another. For example, earthquakes in Japan resulted in long queues for food and water that eventually depleted supplies in supermarkets [7]. However, product substitution can be a viable solution to this problem. Mardan et al. [8] considered product substitution one of the efficient tools to minimize supply uncertainty. According to Transchel [9], substitution behavior reduces the supplydemand imbalance and provides significant profit for firms.

In a single-period multiproduct inventory system, 
Rao et al. [10] considered downward substitution for stochastic demand using a two-stage mixed-integer stochastic program to minimize total costs. Netessine and Rudi [11] studied an optimal stocking problem for a single-period multiproduct consumer-driven substitution under both centralized and decentralized inventory management to maximize profits. Hoseininia et al. [12] considered a multi-channel distribution system where manufacturers and retailers provide substitutable products and sometimes the customer may switch to other channels in case of a stockout. In addition, Yucel et al. [13] developed an optimal policy capable of maximizing the total expected profit over a planning horizon. The authors also determined the effects of substitution on profits by different substitution cost parameters.

Stavrulaki [14] studied the joint effect of demand stimulation and substitution by considering a single-period two-way substitution model. Vaagen et al. [15] developed a heuristic system for consumerdirected substitution using multi-way substitution to address multiproduct stochastic demand and singleperiod inventory management. Bayindir et al. [16] investigated optimal conditions for a single-period profit model under substitution for manufactured and remanufactured products. Kim and Bell [17] studied the effect of substitution in which price is dependent on a company's productivity. In addition, Pentico [18] provided an overview of a detailed survey of assortment problems with substitution.

When a supplier determines the amount to be substituted, it is referred to as "firm-driven substitution" [19-21] . Multi-level demand substitution is a combination of upward and downward substitution strategies. For example, when 1-liter water bottles are out of stock, two half-liter water bottles can be substituted; 1-liter water bottles can be substituted when half-liter water bottles run out of stock.

Figures 1 and 2 present an example where the product weights are given below: $P 1=50 \mathrm{~g}, P 2=$ $100 \mathrm{~g}, P 3=150 \mathrm{~g}$, and $P 4=200 \mathrm{~g}$. Figure 1 illustrates

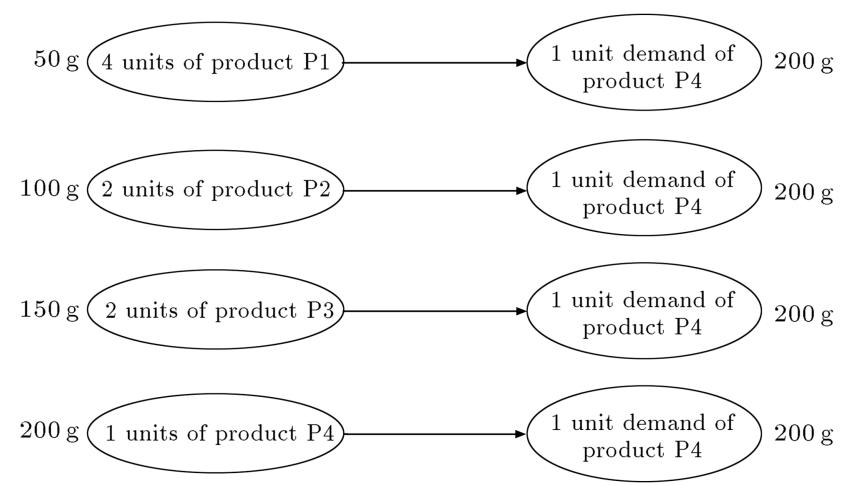

Figure 1. Substitution structure in terms of weight of demand $D 4$ for product $P 4$.

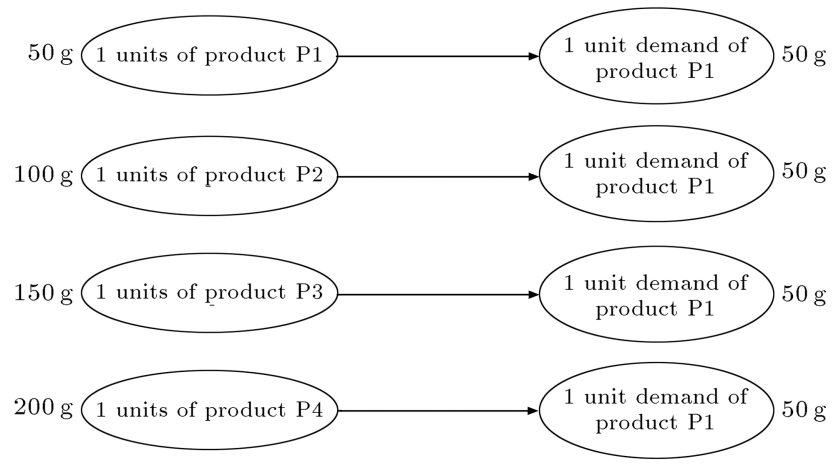

Figure 2. Substitution structure in terms of weight of demand $D 1$ for product $P 1$.

the substitution structure in terms of the weight of demand $D 4$ for product $P 4$, where each unit of demand $D 4$ is substituted by one of the following: four units of product $P 1$, two units of product $P 2$, two units of product $P 3$, or one unit of product $P 4$. Figure 2 shows the substitution structure in terms of the weight of demand D1 for product $P 1$, where each unit of demand $D 4$ is substituted for one of the following: four units of product $P 1$, two units of product $P 2$, two units of product $P 3$, or one unit of product $P 4$.

Extreme weather events easily cause supply chain disruptions. For instance, the drought in Ethiopia reduced crop yield by $90 \%$ [22]. Investigating the effects of substitution on panic buying, Ervolina et al. [23] considered two different customers: customers likely to accept product substitutions and those unlikely to accept substitutions. In panic circumstances and under the pressure of scarcity, most customers are willing to accept products of the same brand as substitutes. Satisfying customers' demand for the majority of overall profits becomes a priority, even at the expense of less valuable customers. Jua et al. [24] segmented suppliers into regular and expedited ones. Hsu et al. [25] considered two products: classified as low indexed and high indexed. Tsao et al. [26] segregated the customers into High-Indexed Stores (HIS) and Low-Indexed Stores (LIS). Shou et al. [3] considered single products when examining panic buying under interruption in supply without substitutions. This study modeled the problem of product segmentation by categorizing retailers (customers) into high-indexed and low-indexed ones. This paper provides an optimal policy for order quantities during panic buying behavior in the first time period and distributes the available inventory effectively to satisfy high index customers in the second time period.

To the best of our knowledge, no study has integrated single-brand, multiple weights of product, the multilevel substitution of product, customer segmentation, and panic buying into a single model. This study considered the firm-driven, customer-segmented substitution for single-brand multi-weighted products 
under panic buying in a two-period model. The goal is to increase the total profit derived from the retail-price, cost of substitution, purchasing cost, lost demand cost, and stock holding cost. To ensure the wholesaler's maximum profit, the optimality of units to be substitutable, ordered, unsatisfied demand, and number of the remaining units are explored. The developed Mixed Integer Program (MIP) model is solved within a few seconds using CPLEX. Here, this research discusses the extent to which variability in interruption in supply influences profits, customer satisfaction provided for high-indexed customers, and overall customer satisfaction and inventory. Moreover, the effect of substitution cost on profits is discussed.

The rest of this paper is sorted out as follows. Section 2 characterizes the problem definition and mathematical model for firm-determined segmented customer substitution under panic buying. Section 3 offers an example and presents the performance analysis of the model in various situations. Section 4 explains the experimental analysis. Section 5 dissects the expansion of the model. Section 6 compares the results obtained by CPLEX and the proposed Genetic Algorithm (GA). Section 7 offers the conclusions and provides recommendations for further research.

\section{Problem definition and mathematical model}

Wholesaler supplies " $w$ " weights of a single product to " $n$ " retail stores over two time periods. Figure 3 presents the flow network for the first time period. The number of products to order represents the total demand in the first time period; in the second time period, the rate of panic $\left(\alpha_{k}\right)$ under heavy demand for products is considered. The remaining products toward the end of the first time period incur an inventory cost. These remaining products toward the finish of the first time period are provided for retailers amid the second

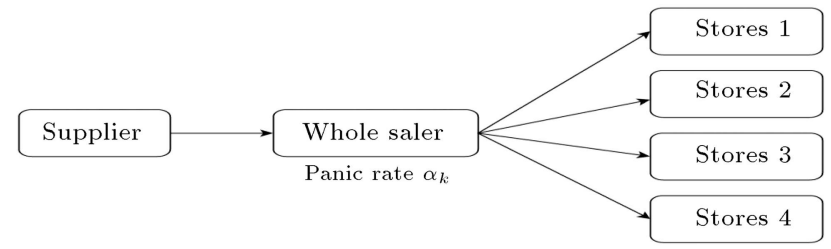

Figure 3. Flow network for first time period. time period. Furthermore, all retail stores are viewed as high indexed in the first time period.

Figure 4 presents the flow network for the second time period. The wholesaler receives $\left(1-\beta_{k}\right)$ of his/her order quantity because supply from the supplier is disrupted. During this time period, the lost demand cost varies if the stores are high indexed or low indexed, and HIS are satisfied before LIS. The wholesaler retains the inventory required, and the retailer's demand is known for all stores. Transshipment is not allowed between retailers. Lost demand costs, cost of substitution, unsatisfied demand, retail-prices, rate of panic, and purchasing costs are known. This study assumes that prices are constant in both periods.

\section{Model}

Assumption

This model assumes that, in both periods, the retailprice " $V_{i, k}$ " is constant, which is reasonable in various situations. For instance, during Hurricane Sandy in 2012 , the attorney general of New Jersey issued a warning of the danger of arraignment during a declared state of emergency to merchants and businesses engaging in price gouging over the top costs for food, fuel, or drugs [27]. What is more, amid the baby's powdered milk lack in Hong Kong, significant providers declared that retail costs were settled [3].

In the first time period, the wholesaler determines the order quantity of products from suppliers based on demand in the first period and rate of panic $\alpha_{k}$. Further, the wholesaler receives the ordered products in full immediately upon issuance. In the second time period, the wholesaler determines the quantity to order according to the interruption in supply $\beta_{k}$, under which the second order cannot be supplied in full, as portrayed by Shou et al. [3] and Tsao et al. [26]. The replenishment and the substitution policy of the model are explained as below:

- At the end of each time period, the wholesaler's inventory is assumed to be replenished. Thus, the total stock includes inventory in the current period and the leftover from the previous period;

- Downward substitution is based on weight; if one 100 -gram pack is out of stock, then two 50-gram packs are substituted to satisfy demand;

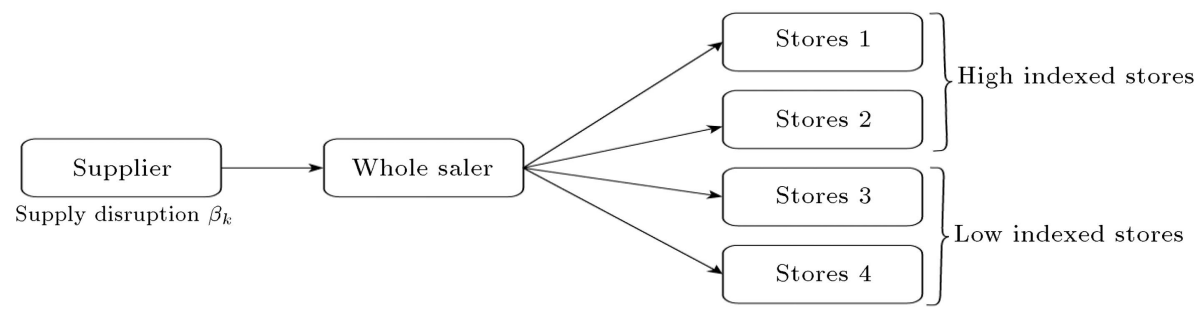

Figure 4. Flow network for second time period. 
- In the case of upward substitution, if one 50-gram pack is out of stock, then one 100-gram pack is substituted for that demand;

- In the first time period, all retailers are viewed as high indexed. In the second time period, the lost demand cost for HIS is higher than that for LIS;

- The cost of substitution $\left(T C_{i, j}\right)$ involves the cost of maintaining goodwill or loss of revenue when $i$ is substituted for $j$.

\section{Constants}

$m \quad$ Total time periods

$n \quad$ Total stores

$o \quad$ Total products

\section{Indices and sets}

$i=(1, \cdots, m)$ Time-periods

$j=(1, \cdots, n)$ Retailers and $n=a+b$, where " $a$ " is a HIS and " $b$ " is a LIS

$k=(1, \cdots, o)$ Products

\section{Parameters}

$V_{i, k} \quad$ Unit price for product $k$ in time period $i$

$C_{i, k} \quad$ Unit cost of purchasing for product $k$

$H C_{k} \quad$ Inventory holding cost per unit of product $k$

$P_{i, j, k} \quad$ Lost demand penalty cost per unit of product $k$ in retailer $j$ for time period $i$

$A_{k, l} \quad$ Quantity substituted per unit of product $k$ substituted per unit of product $l$

$T C_{i, k, l} \quad$ Cost for substituting per unit of product $k$ for product $l$ in retailer $j$ for time period $i$

$D_{i, j, k} \quad$ Product $k$ th demand in retailer $j$ in time period $i$

$T D_{i, k} \quad$ Product $k$ th total demand for in time period $i$

$Z_{1, k} \quad k$ th product initial inventory in time period 1

$\alpha_{k} \quad$ Rate of panic for the $k$ th product

$\beta_{k} \quad$ Rate of interruption in supply for the $k$ th product

\section{Decision variables}

$O_{i, k} \quad$ Quantity of the $k$ th product in time period $i$ to be ordered

$T_{i, j, k, l} \quad$ Amount of the $k$ th product satisfying the $l$ th product demand in store $j$ during time-period $i$

$R_{i, j, k} \quad$ Amount of the $k$ th product received by store $j$ during time period $i$
$S_{i, j, k} \quad$ Amount of the $k$ th product sent to store $j$ during time period $i$

$U_{i, j, k} \quad$ Amount of unsatisfied demand for the $k$ th product in store $j$ during time period $i$

$E_{i, k} \quad$ Amount of the $k$ th product leftover from time period $i$

$H_{i, k} \quad$ Total amount of unit's available satisfying the $k$ th product demands during time period $i$

\section{The Mathematical model}

$$
\begin{aligned}
\max T P= & \sum_{i=1}^{m} \sum_{j=1}^{n} \sum_{k=1}^{o}\left[\left(V_{i, k} \times R_{i, j, k}\right)\right. \\
& -\left(C_{i, k} \times S_{i, j, k}\right) \\
& -\left(\sum_{l=1}^{o} T C_{i, k, l} \times T_{i, j, k, l}\right) \\
& \left.-\left(P_{i, j, k} \times U_{i, j, k}\right)\right] \\
& -\sum_{i=1}^{m} \sum_{k=1}^{o}\left(E_{i, k} \times H C_{k}\right) .
\end{aligned}
$$

Eq. (1) exhibits the objective function that maximizes the total profit, which is the difference between sales revenue and the sum of all costs including purchasing cost, cost of substitution, lost demand penalty, and holding expense.

\section{Distribution constraints}

The number of products $k$ received in stores $j$ and those subsequently distributed by the wholesaler are expressed as in Eqs. (2) and (3), respectively. The quantity received is less than or equal to the quantity sent $\left(R_{i, j, k} \leq S_{i, j, k}\right)$ in view of substitution.

$$
\begin{aligned}
R_{i, j, k} & =\sum_{l=1}^{o} T_{i, j, l, k} / A_{l, k}, \\
\forall i & =1,2 ; \quad j=1,2, \cdots, n ; \quad k=1,2, \cdots, o .
\end{aligned}
$$

\section{Property 1}

where $R_{i, j, k}$ is defined as fractional. Hence, $A_{l, k}$ cannot attain the value zero. In this case, it is always an integer and greater than or equal to one. 


$$
\begin{aligned}
& S_{i, j, k}=\sum_{l=1}^{o} T_{i, j, k, l}, \\
& \quad i=1,2 ; \quad j=1,2, \cdots, n ; \quad k=1,2, \cdots, o .
\end{aligned}
$$

\section{Property 2}

If the retail price is fixed in both time periods, then there is no shortage in the first time period. Hence, the quantity received, quantity sent, and demand in the first time period are equal $\left(R_{1, j, k}=S_{1, j, k}=D_{1, j, k}\right)$. It is not applicable when the retail price is not constant.

The number of units distributed is less than or equivalent to the number of products available and the number of received products is less than or equivalent to the number of units demanded, as denoted by Eqs. (4) and (5):

$$
\begin{aligned}
& \sum_{j=1}^{n} \sum_{l=1}^{o} T_{i, j, k, l} \leq H_{i, k}, \\
& \forall i=1,2, \cdots, m ; \quad k=1,2, \cdots, o, \\
& \sum_{l=1}^{o}\left[T_{i, j, l, k} / A_{l, k}\right] \leq D_{i, j, k}, \\
& \forall i=1,2, \cdots, m ; \quad \forall j=1,2, \cdots, n ; \\
& \quad k=1,2, \cdots, o .
\end{aligned}
$$

\section{Unsatisfied and inventory constraints}

The unsatisfied demand is denoted as in Eq. (6) and is measured by deducting the quantity received to the retailers from the demand. The inventory is determined through Eq. (7):

$$
\begin{aligned}
& U_{i, j, k}=D_{i, j, k}-\sum_{l=1}^{o}\left[T_{i, j, l, k} / A_{l, k}\right], \\
& \forall i=1,2 ; \quad j=1,2, \cdots, n ; \quad k=1,2, \cdots, o, \\
& E_{i, k}=H_{i, k}-\sum_{j=1}^{n} \sum_{l=1}^{o} T_{i, j, k, l}, \\
& \forall i=1 ; \quad k=1,2, \cdots, o .
\end{aligned}
$$

\section{Total units available}

The quantity available is the whole of the inventory left from the time period $i-1$ and the amount ordered during time period $i$ is expressed in Eq. (8). Eq. (9) denotes the number of available units as the aggregate of the underlying stock and the amount ordered during the first time period:

$$
\begin{aligned}
& H_{i, k}=O_{i, k}+E_{i-1, k}, \quad \forall i>1 ; \quad k=1,2, \cdots, o, \\
& H_{1, k}=O_{1, k}+Z_{1, k}, \quad \forall k=1,2, \cdots, o .
\end{aligned}
$$

\section{Total demand}

Eqs. (10) and (11) represent the sum of the total demands of all the stores in the first and second time periods, respectively:

$$
\begin{aligned}
& T D_{1, k}=\sum_{j=1}^{n} D_{1, j, k}, \quad \forall i=1, \quad k=1,2, \cdots, o, \\
& T D_{2, k}=\sum_{j=1}^{n} D_{2, j, k}, \quad \forall i=2, \quad k=1,2, \cdots, o .
\end{aligned}
$$

\section{Order to period assignment constraint}

Eq. (12) denotes the quantity ordered during the first time period, which is the sum of the aggregate demand in the first time period and multiplies the rate of panic $\alpha_{k}$ and whole demand during the second time period. Eq. (13) denotes the amount ordered during the second time period, which is the multiplication of the total of the rate of interruption in supply $\left(1-\beta_{k}\right)$ and rate of panic $\left(1-\alpha_{k}\right)$ and the total demand during the second time period.

$$
\begin{aligned}
& O_{1, k}=T D_{1, k}+\alpha_{k} T D_{2, k}, \\
& \quad \forall 0<\alpha<1 ; \quad j=1,2, \cdots, n ; \quad k=1,2, \cdots, o, \\
& O_{2, k} \leq\left(1-\beta_{k}\right)\left(1-\alpha_{k}\right) T D_{2, k}, \\
& \forall 0<\alpha<1, \quad j=1,2, \cdots, n, \quad k=1,2, \cdots, 0 .
\end{aligned}
$$

\section{Non-negativity constraint}

$$
\begin{aligned}
& T_{i, j, k, l} \geq 0, \text { integer, } \\
& \forall i=1,2, \cdots, m ; \quad j=1,2, \cdots, n ; \quad k=1,2, \cdots, o ; \\
& \quad l=1,2, \cdots o, \\
& U_{i, j, k} \geq 0, \text { integer, } \\
& \forall i=1,2, \cdots, m ; \quad j=1,2, \cdots, n ; \quad k=1,2, \cdots, o,
\end{aligned}
$$

$$
\begin{aligned}
O_{i, k} & \geq 0, \text { integer, } \\
\forall i & =1,2, \cdots, m ; \quad k=1,2, \cdots, o .
\end{aligned}
$$

The developed MIP model is solved in CPLEX that provides optimal solutions for the proposed model under all of the tested instances. 


\section{Penalty cost}

The lost demand cost segregates the customers into LIS and HIS. The lost demand cost of LIS is expressed as $P_{i, b, k}=\eta \times$ the retail-price of the $k$ th product $(0<\eta<1)$ and that for high-indexed customers is expressed as $P_{i, a, k}=\eta \times$ the retail-price of the $k$ th product $+\max \left(P_{i, b, k}\right)$.

\section{Property 3}

The penalty cost of HIS is always greater than the LIS $\left(P_{i, a, k}>P_{i, b, k}\right)$. If the penalty costs of all customers are equal, then there is no segregation of customers $\left(P_{i, a, k}=P_{i, b, k}\right)$.

\section{Numerical example}

This study provides a numerical example from Tsao et al. [26] and represents the data for demand. A scenario that involves four products (P1, P2, P3, and $\mathrm{P} 4$ ), four stores, and two periods is considered. The products were of the same brand in different quantities (weights). The weights of the products from P1 to P4 are $50 \mathrm{~g}, 100 \mathrm{~g}, 150 \mathrm{~g}, 200 \mathrm{~g}$, respectively. Table 1 shows the parameter of retail-price and cost components of each product. Table 2 shows the cost of substitution products for retailers in both time periods. The ratio of substitution products in both time periods depends on the weights of products (Table 3 ). In addition, the rate of panic, interruption in supply, and initial inventory are given as $\alpha_{k}=\{0.3,0.3,0.3,0.3\}, \beta_{k}=$ $\{0,0,0.7,0.8\}$, and $Z_{1, k}=\{3500,2700,1370,1770\}$, respectively. In the first time period, all retailers

Table 1. Parameter of retail-price and cost components of each product.

\begin{tabular}{|c|c|c|c|c|}
\hline & \multicolumn{3}{|c|}{ Parameter } \\
\hline & & $\begin{array}{c}V_{i, k} \text { in both } \\
\text { time-periods } \\
\text { (Rs) }\end{array}$ & $\begin{array}{c}C_{i, k} \text { in both } \\
\text { time-periods } \\
(\mathrm{Rs})\end{array}$ & $\begin{array}{c}H C_{k} \text { in both } \\
\text { time-periods } \\
\text { (Rs) }\end{array}$ \\
\hline \multirow{4}{*}{ 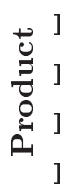 } & $\mathbf{P 1}$ & 12 & 7 & 3 \\
\hline & P2 & 24 & 14 & 6 \\
\hline & P 3 & 36 & 21 & 9 \\
\hline & $\mathbf{P} 4$ & 48 & 28 & 12 \\
\hline
\end{tabular}

Table 2. Cost of substitution products for retailers in both time periods.

\begin{tabular}{ccccc}
\hline Product & P1 & P2 & P3 & P4 \\
\hline P1 & - & 8 & 8 & 8 \\
P2 & 15 & - & 15 & 8 \\
P3 & 22 & 15 & - & 22 \\
P4 & 24 & 22 & 15 & - \\
\hline
\end{tabular}

Table 3. Ratio of substitution products in both time periods.

\begin{tabular}{ccccc}
\hline Product & P1 & P2 & P3 & P4 \\
\hline P1 & One & Two & Three & Four \\
P2 & One & One & Two & Two \\
P3 & One & One & One & Two \\
P4 & One & One & One & One \\
\hline
\end{tabular}

are considered as high indexed and, in the second time period, retailers 1 and 2 are considered as high indexed; hence, the lost demand cost of HIS is $P_{1, k}=$ $\{24,28.8,33.6,38.4\}$. In the second time period, Retailers 3 and 4 are considered as LIS; hence, the lost demand cost of the LIS is $P_{2, k=2,4}=\{4.8,9.6,14.4,19.2\}$. No interruption in supply occurred for Products 1 and 2 ; however, the interruption in supply rates for the $3 \mathrm{rd}$ and 4 th products was 0.7 and 0.8 , respectively.

Table 4 shows an optimal solution for each product that should be distributed to the retail stores. When there is no substitutable product in the first time period, one can expect the onset of panic. As a result of interruption in the supply in the second time period, the substitution is executed in the second time period to maximize the aggregate profit and encourage customer satisfaction in the high-indexed retailer. The substitution units are provided from the overabundance stock and the order quantity of the low-indexed customers. The profits obtained Without Customer Segmentation Substitution (WOCSS) model and With Customer Segmentation Substitution (WCSS) model are Rs. 1127636 and Rs. 1168943. As indicated by the highlighted values in Table 4, nearly 10670 units are used for substitution by the wholesaler and stores, based on the weight ratio, received 4752 units. $X, Y$, $Z$ denote the substitution of the products in Table 4 .

\section{Experimental analysis}

For experimental reproductions, the cases involving four products and four stores over two periods are generated. To initiate the experimental analysis, the parameter of brand $\mathrm{G}$ from Tsao et al. [26] is used, and the same is used for Sections 5 and 6 .

\subsection{Impact of variation in substitution costs on profits}

Figure 5 shows that increasing the substitution cost as a percentage of product cost leads to a decrease in total profits: $T C_{i, k, l}=\theta \times$ purchasing cost + loss in purchasing cost $(0<\theta<1)$. Figure 5 illustrates the effects of variation in substitution cost on the profit in WOCSS and WCSS models. As demonstrated, profit increases as $\theta$ decreases and, also, the profit continually increases under customer-segmented substitution. 
Table 4. Distribution of quantity obtained from CPLEX (units).

\begin{tabular}{|c|c|c|c|c|c|c|}
\hline \multirow{6}{*}{ 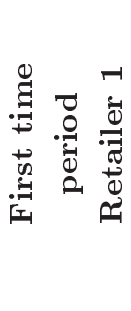 } & & P1 & P2 & P3 & P 4 & $\begin{array}{l}\text { Profit } \\
\text { (in Rs) }\end{array}$ \\
\hline & P1 & 7041 & & & & \multirow{47}{*}{ 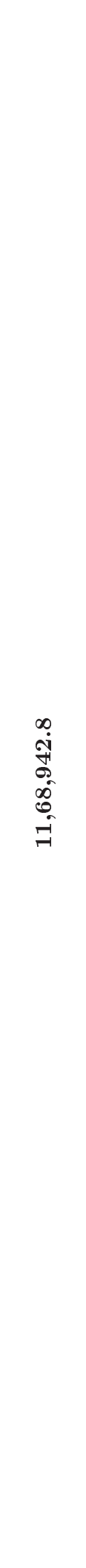 } \\
\hline & P2 & & 7515 & & & \\
\hline & P3 & & & 6530 & & \\
\hline & P4 & & & & 7293 & \\
\hline & Total & 7041 & 7515 & 6530 & 7293 & \\
\hline \multirow{6}{*}{ 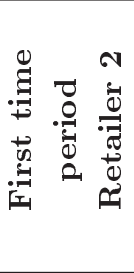 } & & P1 & P2 & P3 & P4 & \\
\hline & P1 & 7028 & & & & \\
\hline & P2 & & 6840 & & & \\
\hline & P3 & & & 7383 & & \\
\hline & $\mathbf{P} 4$ & & & & 7658 & \\
\hline & Total & 7028 & 6840 & 7383 & 7658 & \\
\hline \multirow{6}{*}{ 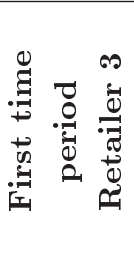 } & & P1 & P2 & P3 & P4 & \\
\hline & P1 & 3141 & & & & \\
\hline & P2 & & 3830 & & & \\
\hline & P3 & & & 2928 & & \\
\hline & $\mathbf{P} 4$ & & & & 2992 & \\
\hline & Total & 3141 & 3830 & 2928 & 2992 & \\
\hline \multirow{6}{*}{ 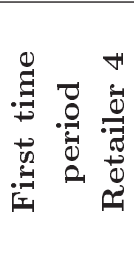 } & & $\mathbf{P 1}$ & P2 & P3 & $\mathbf{P} 4$ & \\
\hline & P1 & 3046 & & & & \\
\hline & P2 & & 3945 & & & \\
\hline & P3 & & & 2830 & & \\
\hline & $\mathbf{P} 4$ & & & & 3992 & \\
\hline & Total & 3046 & 3945 & 2830 & 3992 & \\
\hline \multirow{6}{*}{ 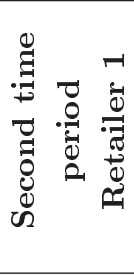 } & & P1 & P2 & P3 & P 4 & \\
\hline & P1 & 7850 & & & & \\
\hline & P2 & & 6771 & & & \\
\hline & P3 & & & 6155 & & \\
\hline & $\mathbf{P} 4$ & & & & 7025 & \\
\hline & Total & 7850 & 6771 & 6155 & 7025 & \\
\hline \multirow{6}{*}{ 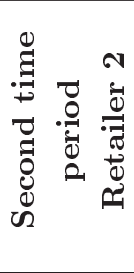 } & & P1 & P2 & P3 & $\mathrm{P} 4$ & \\
\hline & $\mathbf{P 1}$ & 6778 & & $3498^{X}$ & & \\
\hline & P2 & & 7781 & & $7172^{Y}$ & \\
\hline & P3 & & & 6462 & & \\
\hline & $\mathbf{P} 4$ & & & & 3758 & \\
\hline & Total & 6778 & 7781 & 7628 & 7344 & \\
\hline \multirow{6}{*}{ 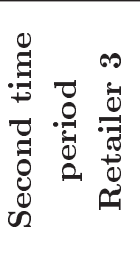 } & & P1 & P2 & P3 & $\mathrm{P} 4$ & \\
\hline & P1 & 3046 & & & & \\
\hline & P2 & & & & & \\
\hline & P3 & & & & & \\
\hline & P4 & & & & & \\
\hline & Total & 3046 & - & - & - & \\
\hline \multirow{6}{*}{ 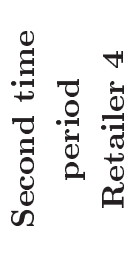 } & & P1 & $\mathbf{P} 2$ & P3 & P4 & \\
\hline & P1 & 3357 & & & & \\
\hline & P2 & & 1091 & & & \\
\hline & P3 & & & & & \\
\hline & P 4 & & & & & \\
\hline & Total & 3357 & 1091 & - & - & \\
\hline
\end{tabular}

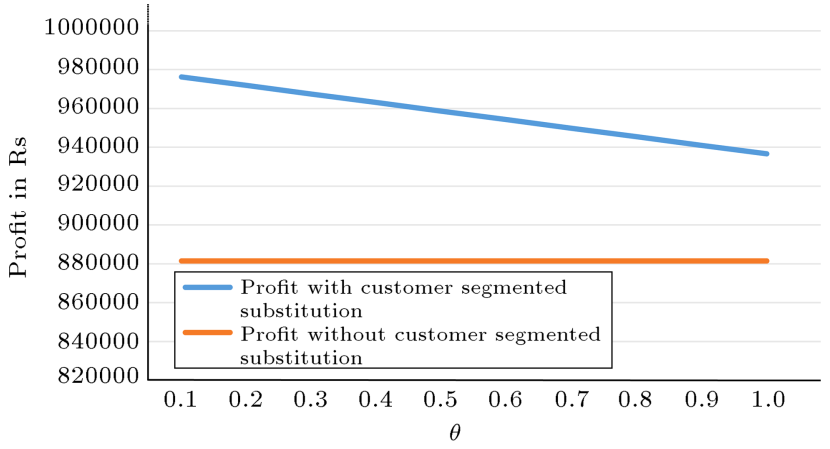

Figure 5. Impact of increasing $\theta$ on profit in the Without Customer Segmentation Substitution (WOCSS) and With Customer Segmentation Substitution (WCSS) models.

\subsection{Impact of variation in interruption in supply}

The rate at which supply becomes disrupted is modified to examine the performance of WOCSS and WCSS models. In reality, the degree of interruption in the supply is not really the same for all products. The simulation considered no interruption in supply $\left(\beta_{1,2}=\{0,0\}\right)$ for Products 1 and 2 and changes the rates of interruption in supply $\left(\beta_{3,4}\right)$ for the 3 rd and 4th products. Table 5 shows the correlation of the impacts of the WOCSS and WCSS models when $\beta_{3,4}$ increases. The results are analyzed in the following section.

\subsubsection{Impact on total profit}

The rate of interruption in supply for the 3rd and 4th products changes from 0 to 1 and their effects on total profit are analyzed in the cases of both WOCSS and WCSS models. Figure 6 exhibits the pronounced effect of increased interruption in supply on profits when customer-segmented substitution is conducted. The profits increased by as much as $17 \%$ when excess products and the order quantity of the low-indexed customer are substituted for items that were out of stock, giving preference to high-indexed customers.

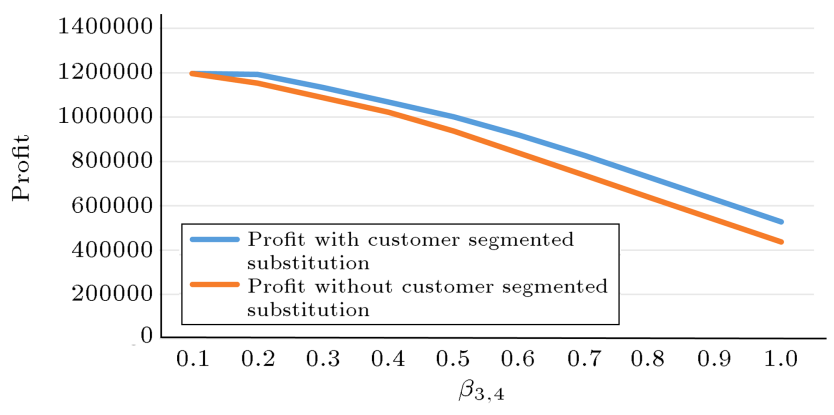

Figure 6. Impact on total profit while increasing $\beta_{3,4}$ in the Without Customer Segmentation Substitution (WOCSS) and With Customer Segmentation Substitution (WCSS) models. 
Table 5. Correlation of Without Customer Segmentation Substitution (WOCSS) and With Customer Segmentation Substitution (WCSS) models while increasing $\beta_{3,4}$.

\begin{tabular}{|c|c|c|c|c|c|c|c|c|c|}
\hline $\begin{array}{c}\text { Rate of } \\
\text { interruption } \\
\text { in supply }\end{array}$ & $\begin{array}{c}\text { Total } \\
\text { profit } \\
(\text { WCSS })\end{array}$ & $\begin{array}{c}\text { Total } \\
\text { profit } \\
\text { (WOCSS) }\end{array}$ & $\begin{array}{c}\text { Increase in } \\
\text { total profit } \\
(\%)\end{array}$ & $\begin{array}{c}\text { HIS } \\
\text { customer } \\
\text { satisfaction } \\
(\text { WCSS }) \\
(\%)\end{array}$ & $\begin{array}{c}\text { HIS } \\
\text { customer } \\
\text { satisfaction } \\
(\text { WOCSS }) \\
(\%) \\
\end{array}$ & $\begin{array}{c}\text { Overall } \\
\text { customer } \\
\text { satisfaction } \\
(\text { WCSS }) \\
(\%) \\
\end{array}$ & $\begin{array}{c}\text { Overall } \\
\text { customer } \\
\text { satisfaction } \\
\text { (WOCSS) } \\
(\%) \\
\end{array}$ & $\begin{array}{c}\text { Units } \\
\text { leftover } \\
\text { (WCSS) }\end{array}$ & $\begin{array}{c}\text { Units } \\
\text { leftover } \\
\text { (WOCSS) }\end{array}$ \\
\hline 0.1 & 1196046 & 1196046 & 0 & 100 & 100.00 & 100 & 100 & 18016 & 18016 \\
\hline 0.2 & 1192282 & 1153750 & 3.23 & 100.00 & 100.00 & 100.00 & 98.57 & 14427 & 17525 \\
\hline 0.3 & 1133289 & 1087934 & 4.00 & 100.00 & 100.00 & 98.17 & 96.56 & 14127 & 17525 \\
\hline 0.4 & 1067465 & 1022110 & 4.25 & 100.00 & 100.00 & 96.16 & 94.55 & 14127 & 17525 \\
\hline 0.5 & 1001687 & 936744 & 6.48 & 100.00 & 98.46 & 94.15 & 92.55 & 14127 & 17525 \\
\hline 0.6 & 919006 & 836725 & 8.95 & 100.00 & 95.78 & 89.74 & 90.54 & 14127 & 17525 \\
\hline 0.7 & 827152 & 736761 & 10.93 & 98.73 & 93.10 & 86.48 & 88.53 & 14127 & 17525 \\
\hline 0.8 & 727276 & 636863 & 12.43 & 96.05 & 90.42 & 84.47 & 86.52 & 14127 & 17525 \\
\hline 0.9 & 627288 & 536897 & 14.41 & 93.35 & 87.74 & 82.46 & 84.52 & 14127 & 17525 \\
\hline 1 & 527388 & 436997 & 17.14 & 90.69 & 85.06 & 80.46 & 82.51 & 14127 & 17525 \\
\hline
\end{tabular}

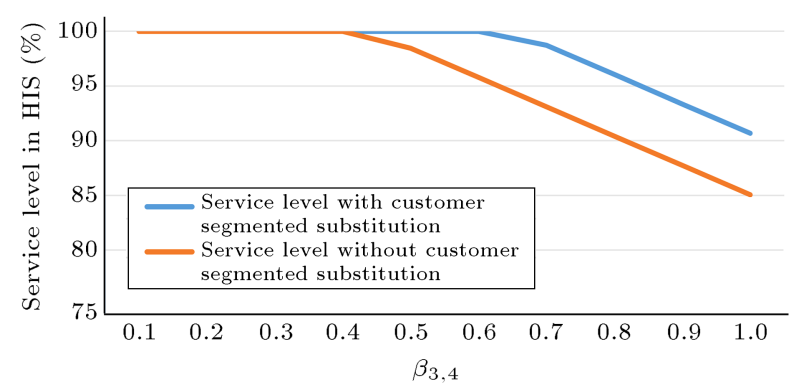

Figure 7. Impact on percent of customer satisfaction obtained in high- and low-indexed retailers while increasing $\beta_{3,4}$ in the Without Customer Segmentation Substitution (WOCSS) and With Customer Segmentation Substitution (WCSS) models.

\subsubsection{Impact on percentage of customer satisfaction obtained in HIS}

This study examined the percentage of customer satisfaction received by the high-indexed retailer in the WOCSS and WCSS models when the rates of supply were interrupted between 0 and 1 for the $3 \mathrm{rd}$ and 4 th products. Figure 7 illustrates the effect of customersegmented substitution on customer satisfaction. The customer satisfaction of HIS increased under customersegmented substitution. To satisfy the demand from HIS, excess inventory is substituted in the first substitution phase, whereas the excess inventory is substituted and orders are deallocated from LIS in the second phase.

\subsubsection{Impact on percentage of overall customer satisfaction obtained in retailers}

This study analyzed the percentage of overall customer satisfaction in the retailers for the WOCSS and WCSS models when the rate of supply is interrupted between 0 and 1 for the 3 rd and 4 th products. Figure 8 illustrates that the overall customer satisfaction per-

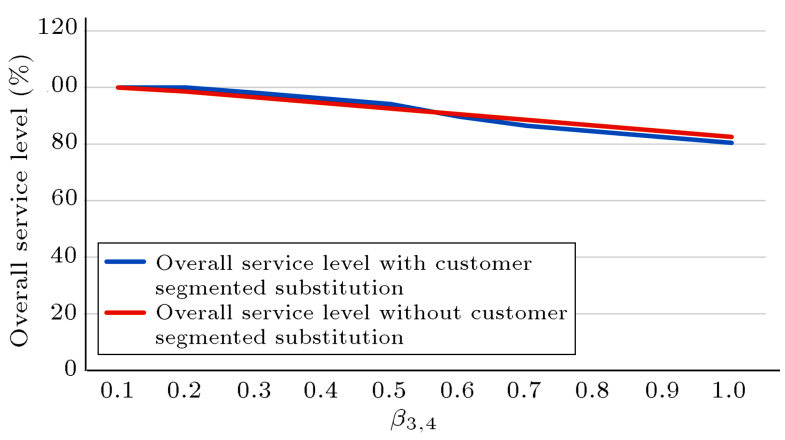

Figure 8. Impact on the overall percentage customer satisfaction while increasing $\beta_{3,4}$ in the Without Customer Segmentation Substitution (WOCSS) and With Customer Segmentation Substitution (WCSS) models.

centage is higher in the first substitution phase under the customer-segmented substitution model. However, in the second substitution phase, the deallocation of the orders of low-indexed customers caused overall customer satisfaction in WCSS to be lower than that in cases without customer-segmented substitution.

\subsubsection{Impact on inventory}

The effect of varying interruptions in supply rates for the 3 rd and 4 th products on the inventory held by the wholesaler is analyzed. The inventory was constant during the first time period since substitution has not been actualized yet. In the second time period, the abundance inventory in the wholesaler is utilized for the substitution of products, thereby decreasing the available units leftover to zero. In this case, the rate of interruption in the supply rate is 0.1 and the inventory available during the second time period is higher than zero regardless of whether the substitution is implemented. Whenever the rate of interruption in supply is 0.2 , the inventory available during the second time period is zero in the case of substitution. 


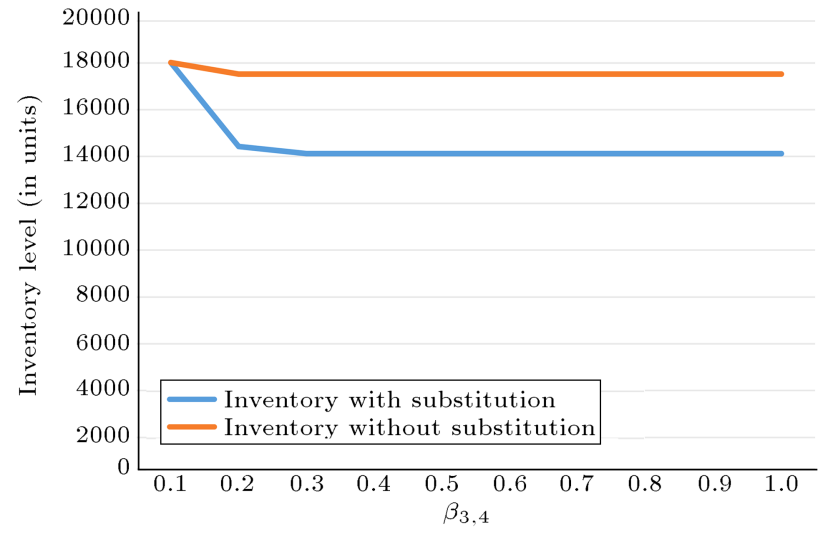

Figure 9. Impact on inventory while increasing $\beta_{3,4}$ in the Without Customer Segmentation Substitution (WOCSS) and With Customer Segmentation Substitution (WCSS) models.

Figure 9 clearly illustrates that the available units remain consistent when the interruption in supply rate is above 0.2. Because the rate of panic is constant, the maximum allowable order quantity in the first time period is attained whenever interruption in the supply rate is 0.2 . The inventory relies on the substitutable product rate, rate of panic, and initial units' leftover.

\subsection{Impact in constant interruption in supply for all products}

Suppose that the interruption in supply is even for all products. Even if it is rarely possible, Table 6 compares WOCSS and WCSS models. In compliance with the same data in the numerical example, the profits in WOCSS and WCSS are correlated under different interruptions in the supply rate (from 0.1 to 1). Overall, the customer segmented substitution model performs better (higher profit) than the model without substitution.
4.4. Impact of variation in the rate of panic The rate of panic is modified to analyze the performance of WOCSS and WCSS models. This study considers that there is no panic $\left(\alpha_{1,2}=\{0,0\}\right)$ for Products 1 and 2 and rate of panic $\left(\alpha_{3,4}\right)$ varies for the 3 rd and 4 th products. Table 7 presents the correlation of WOCSS and WCSS models when $\alpha_{3,4}$ increases, where the interruption in the supply of products remains constant as $\beta_{k}=\{0,0,0.5,0.6\}$. The results are analyzed in the following section.

\subsubsection{Impact on total profit}

The rate of panic for the $3 \mathrm{rd}$ and 4 th products varies from 0 to 1 and its effects on the total profit are analyzed in cases of WOCSS and WCSS models. Figure 10 illustrates that the rate of panic increases when the WCSS model is applied, leading to an increase in profits. In the WCSS model, the profit increases when the rate of panic is 0.8 and decreases afterward. The increase in the rate of panic will increase the inventory within the first time period and reduce the interruption

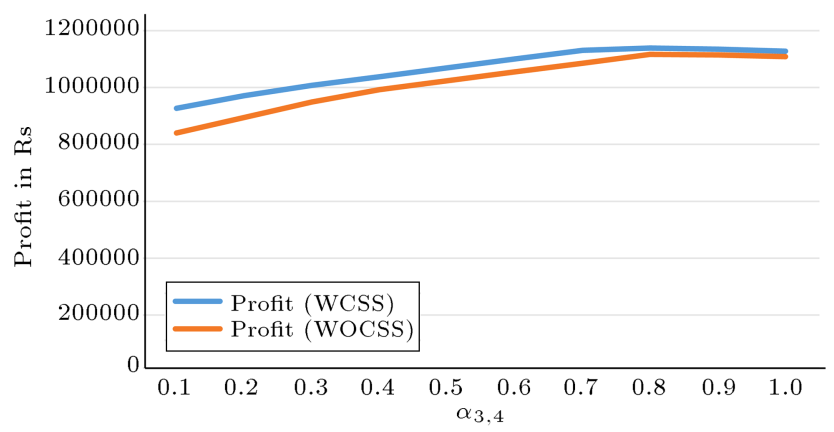

Figure 10. Impact on total profit while increasing $\alpha_{3,4}$ in the Without Customer Segmentation Substitution

(WOCSS) and With Customer Segmentation Substitution (WCSS) models.

Table 6. Impact on the Without Customer Segmentation Substitution (WOCSS) and With Customer Segmentation Substitution (WCSS) models while $\beta_{\text {(constant for all products) }}$ and $\alpha=0.3$.

\begin{tabular}{cccccc}
\hline $\begin{array}{c}\text { Rate of } \\
\text { interruption } \\
\text { in supply }\end{array}$ & $\begin{array}{c}\text { Total } \\
\text { profit } \\
\text { (WCSS) }\end{array}$ & $\begin{array}{c}\text { Total } \\
\text { profit } \\
\text { (WOCSS) }\end{array}$ & $\begin{array}{c}\text { Increase in } \\
\text { total profit } \\
(\mathbf{\%})\end{array}$ & $\begin{array}{c}\text { HIS customer } \\
\text { satisfaction } \\
\text { (WCSS) } \\
(\boldsymbol{\%})\end{array}$ & $\begin{array}{c}\text { HIS customer } \\
\text { satisfaction } \\
\text { (WOCSS) } \\
(\%)\end{array}$ \\
\hline 0.1 & 1198144 & 1198144 & 0 & 100 & 100 \\
0.2 & 1159445 & 1155413 & 0.35 & 100 & 100 \\
0.3 & 1079773 & 1079773 & 0 & 100 & 100 \\
0.4 & 997592 & 997592 & 0 & 100 & 100 \\
0.5 & 915152 & 915062 & 0.01 & 100 & 99.97 \\
0.6 & 797768 & 796828 & 0.12 & 97.29 & 97.14 \\
0.7 & 658749 & 658749 & 0 & 92.75 & 92.75 \\
0.8 & 516815 & 516815 & 0 & 71.28 & 71.28 \\
0.9 & 374881 & 374881 & 0 & 66.59 & 66.59 \\
1 & 233106 & 233106 & 0 & 61.90 & 61.90 \\
\hline
\end{tabular}


Table 7. Correlation of Without Customer Segmentation Substitution (WOCSS) and With Customer Segmentation Substitution (WCSS) models while increasing $\alpha_{3,4}$.

\begin{tabular}{|c|c|c|c|c|c|c|c|c|c|}
\hline $\begin{array}{c}\text { Rate } \\
\text { of } \\
\text { panic }\end{array}$ & $\begin{array}{c}\text { Profit } \\
\text { (WCSS) }\end{array}$ & $\begin{array}{c}\text { Profit } \\
\text { (WOCSS) }\end{array}$ & $\begin{array}{c}\text { Increase } \\
\text { in profit } \\
(\%)\end{array}$ & $\begin{array}{c}\text { Customer } \\
\text { satisfaction } \\
(\text { WCSS }) \\
(\%)\end{array}$ & $\begin{array}{c}\text { Customer } \\
\text { satisfaction } \\
\text { (WOCSS) } \\
(\%)\end{array}$ & $\begin{array}{c}\text { Overall } \\
\text { customer } \\
\text { satisfaction } \\
\text { (WCSS) } \\
(\%)\end{array}$ & $\begin{array}{c}\text { Overall } \\
\text { customer } \\
\text { satisfaction } \\
\text { (WOCSS) } \\
(\%)\end{array}$ & $\begin{array}{c}\text { Inventory } \\
\text { (WCSS) }\end{array}$ & $\begin{array}{l}\text { Inventory } \\
\text { (WOCSS) }\end{array}$ \\
\hline 0.1 & 927047 & 839842 & 9.41 & 100 & 95.26 & 89.34 & 90.15 & 7733 & 11133 \\
\hline 0.2 & 971456 & 894284 & 7.94 & 100 & 97.11 & 92.51 & 91.53 & 9865 & 13264 \\
\hline 0.3 & 1007420 & 948665 & 5.83 & 100 & 98.95 & 94.52 & 92.91 & 11999 & 15399 \\
\hline 0.4 & 1038344 & 992889 & 4.38 & 100 & 100.00 & 95.90 & 94.30 & 14134 & 17534 \\
\hline 0.5 & 1069287 & 1023887 & 4.25 & 100 & 100.00 & 97.18 & 95.68 & 16267 & 19667 \\
\hline 0.6 & 1100187 & 1054792 & 4.13 & 100 & 100.00 & 98.66 & 97.06 & 18400 & 21800 \\
\hline 0.7 & 1130796 & 1085716 & 3.99 & 100 & 100.00 & 100.00 & 98.44 & 20455 & 23935 \\
\hline 0.8 & 1138996 & 1116654 & 1.96 & 100 & 100.00 & 100.00 & 99.82 & 19626 & 26068 \\
\hline 0.9 & 1134170 & 1114970 & 1.69 & 100 & 100.00 & 100.00 & 100.00 & 20378 & 27178 \\
\hline 1 & 1127560 & 1108360 & 1.70 & 100 & 100.00 & 100.00 & 100.00 & 21336 & 28136 \\
\hline
\end{tabular}

in supply in the 2nd time period. In the WCSS model when the rate of panic is 0.7 , a number of Products 1 and 2 are stored in inventory to fulfill the demand of Products 3 and 4 . Therefore, above 0.7 , the need to stock excess quantity from Products 1 and 2 decreases and, hence, the inventory reduces. In any case, growth in the rate of panic elevates the remaining products in the unit in the first time period and, then, reduces aggregate profit.

\subsubsection{Impact on percentage of customer satisfaction obtained in high-indexed retailers}

The percentage of customer satisfaction received by HIS in WOCSS and WCSS is examined here when the rate of panic for the $3 \mathrm{rd}$ and 4 th products varies between 0 and 1. Figure 11 shows the effect of the WCSS model on the customer satisfaction level. The WOCSS at a low rate of panic in the initial stages reduces the

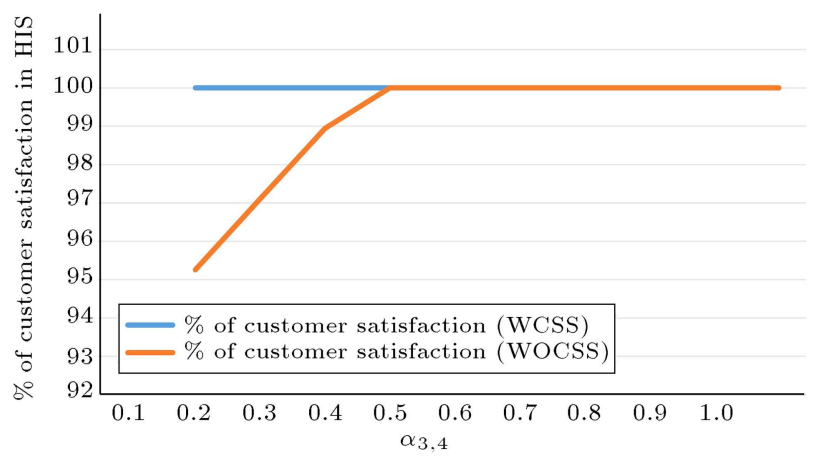

Figure 11. Impact on percent of customer satisfaction obtained in high- and low-indexed retailers while increasing $\alpha_{3,4}$ in the Without Customer Segmentation Substitution (WOCSS) and With Customer Segmentation Substitution (WCSS) models. inventory in the first time period; hence, customer satisfaction for the HIS is reduced. In general, the WCSS enjoys better performance than the WOCSS.

\subsubsection{Impact on percentage of overall customer satisfaction obtained in retailers}

The overall customer satisfaction in the case of retailers at different rates of panic (0-1) for the 3rd and 4 th products for both WOCSS and WCSS is analyzed. Figure 12 illustrates that the first and second substitution phases occur in the beginning because of the deallocation of the orders of low-indexed customers. Hence, the overall customer satisfaction in WCSS is lower than that in WOCSS in the beginning. One can expect substitution in the first phase (rate of panic being 0.2 to 0.7 ) when the inventory in the first time period increases; in addition, in case of further growth in inventory, there may be no substitution (rate of panic being 0.8 to 1 ).

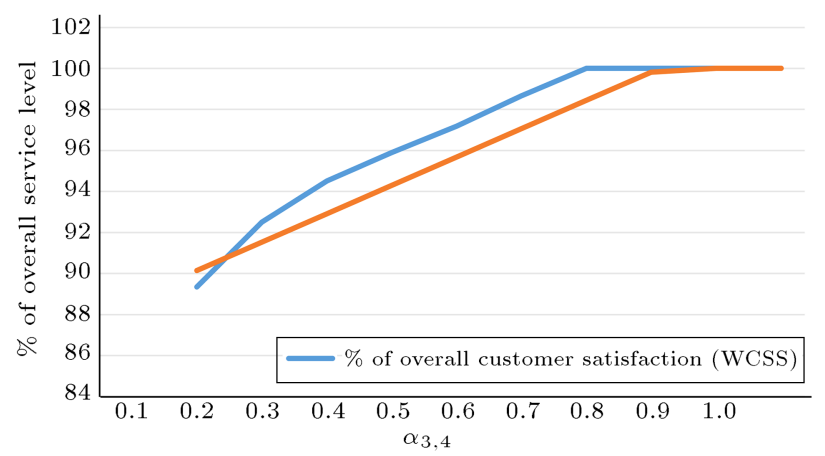

Figure 12. Impact on the overall percentage customer satisfaction while increasing $\alpha_{3,4}$ in the Without Customer Segmentation Substitution (WOCSS) and With Customer Segmentation Substitution (WCSS) models. 


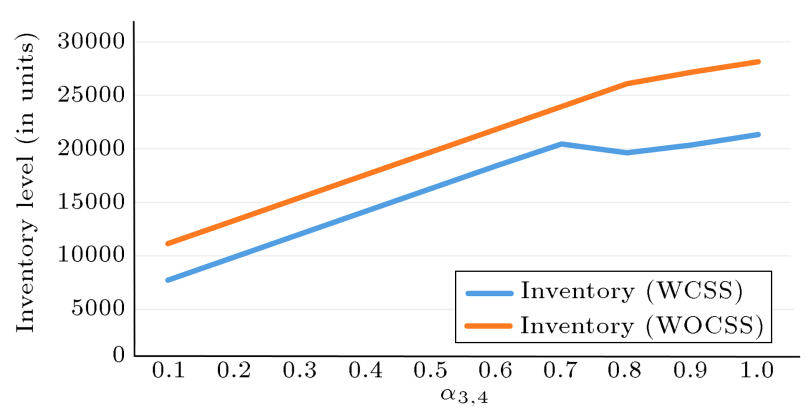

Figure 13. Impact on inventory while increasing $\alpha_{3,4}$ in the Without Customer Segmentation Substitution (WOCSS) and With Customer Segmentation Substitution (WCSS) models.

\subsubsection{Impact on inventory}

The effect of different rates of panic for Products 3 and 4 on the inventory held by the wholesaler is analyzed. Figure 13 clearly illustrates that units leftover increase gradually when the rate of panic increases. Increase in the rate of panic increases the inventory in the first time period and decreases the amount of interruption in supply in the second time period. As discussed in Section 4.4.1, in the WCSS, the unit's leftover increases when the rate of panic is 0.7 and decreases to above 0.7. Finally, due to an increase in the rate of panic, the unit's leftover increase to above 0.8 .

\section{Impact of price change}

All of the periods in the case of the retail price $\left(V_{i, k}\right)$ are constant in the previous sections. In this section, the retail price in the second time period rises when the rate of interruption in supply increases. Dixit and Pindyck [28] provided the model as a function of price for both cases of the retail price increase and decrease. Later on, $\mathrm{Li}$ and Kouvelis [29] considered the model as a function of price for both cases of retail price increase and decrease and assumed constant demand to be independent of the retail price. Tsao et al. [26] considered the retail price increase in the second time period as $V_{2, k}=V_{1, k}+\beta_{k}\left(P_{\max , K}-V_{1, k}\right)$ and assumed $\mathrm{V} 1, \mathrm{k}$ to be a retail price in the first time period, where $P_{\max , K}$ denotes the permitted increased retail price, which remains unchanged. Interruption in supply determines the retail price rise.

In this case, there is no interruption in supply $\left(\beta_{1,2}=\{0,0\}\right)$ for the 1st and 2 nd products and that the interruption of supply rates $\left(\beta_{3,4}\right)$ for the 3 rd and 4 th products varies. In addition, in this experimental analysis, $P_{\max , K}=1.5 * V_{1, k}$. Table 8 shows the impact of the WOCSS and WCSS models with respect to a rise in $\beta_{3,4}$. The outcomes are investigated.

\subsection{Impact on total profit}

The rate of interruption in supply for the 3rd and 4th products varies between 0 and 1 and its effects on total profit are investigated. Figure 14 shows that increase in the price and interruption in supply in this case had

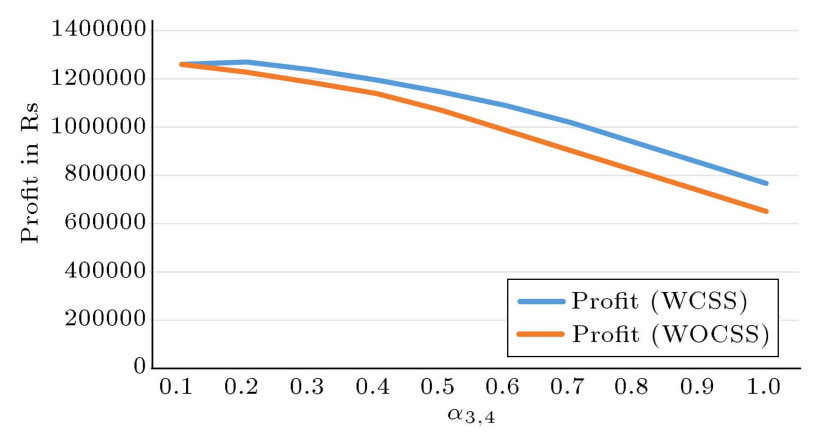

Figure 14. Impact on total profit while increasing $\beta_{3,4}$ in the Without Customer Segmentation Substitution (WOCSS) and With Customer Segmentation Substitution (WCSS) models.

Table 8. Correlation of Without Customer Segmentation Substitution (WOCSS) and With Customer Segmentation Substitution (WCSS) models while increasing $\beta_{3,4}$.

\begin{tabular}{|c|c|c|c|c|c|c|c|c|c|}
\hline $\begin{array}{c}\text { Rate of } \\
\text { interruption } \\
\text { in supply }\end{array}$ & $\begin{array}{c}\text { Total } \\
\text { profit } \\
(\text { WCSS })\end{array}$ & $\begin{array}{c}\text { Total } \\
\text { profit } \\
(\text { WOCSS })\end{array}$ & $\begin{array}{c}\text { Increase in } \\
\text { total profit } \\
(\%)\end{array}$ & $\begin{array}{c}\text { HIS } \\
\text { customer } \\
\text { satisfaction } \\
(\text { WCSS }) \\
(\%)\end{array}$ & $\begin{array}{c}\text { HIS } \\
\text { customer } \\
\text { satisfaction } \\
\text { (WOCSS) } \\
(\%)\end{array}$ & $\begin{array}{c}\text { Overall } \\
\text { customer } \\
\text { satisfaction } \\
(\text { WCSS }) \\
(\%)\end{array}$ & $\begin{array}{c}\text { Overall } \\
\text { customer } \\
\text { satisfaction } \\
\text { (WOCSS) } \\
(\%)\end{array}$ & $\begin{array}{c}\text { Units } \\
\text { leftover } \\
\text { (WCSS) }\end{array}$ & $\begin{array}{c}\text { Units } \\
\text { leftover } \\
\text { (WOCSS) }\end{array}$ \\
\hline 0.1 & 1259865.50 & 1259865.5 & 0 & 100 & 100 & 100 & 100 & 10238 & 10238 \\
\hline 0.2 & 1269469 & 1226763 & 3.36 & 100.00 & 100.00 & 100.00 & 98.57 & 13827 & 16925 \\
\hline 0.3 & 1237431 & 1184883.5 & 4.25 & 100.00 & 100.00 & 98.17 & 96.56 & 14125 & 17521 \\
\hline 0.4 & 1194353 & 1139408 & 4.60 & 100.00 & 100.00 & 96.16 & 94.55 & 14125 & 17521 \\
\hline 0.5 & 1145358 & 1070100 & 6.57 & 100.00 & 98.46 & 93.34 & 92.55 & 14127 & 18504 \\
\hline 0.6 & 1088497 & 986065 & 9.41 & 100.00 & 95.78 & 88.88 & 90.54 & 14126 & 20212 \\
\hline 0.7 & 1018182 & 902217 & 11.39 & 98.73 & 93.10 & 86.48 & 88.53 & 14935 & 21919 \\
\hline 0.8 & 934342 & 818377 & 12.41 & 96.05 & 90.42 & 84.47 & 86.52 & 16641 & 23625 \\
\hline 0.9 & 850396 & 734465 & 13.63 & 93.37 & 87.74 & 82.46 & 84.52 & 18349 & 25332 \\
\hline 1 & 766588 & 650625 & 15.13 & 90.69 & 85.06 & 80.46 & 82.51 & 20055 & 27038 \\
\hline
\end{tabular}




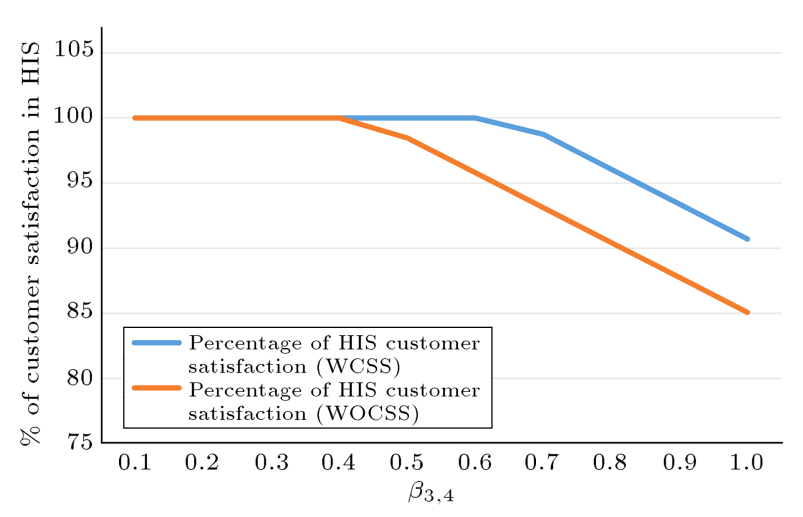

Figure 15. Impact on percent of customer satisfaction obtained in high- and low-indexed retailers while increasing $\beta_{3,4}$ in the Without Customer Segmentation Substitution (WOCSS) and With Customer Segmentation Substitution (WCSS) models.

pronounced effect on profits in the case of customersegmented substitution. Another critical problem is stocking/hoarding behavior. Because of a rise in the retail price in the second time period, which exceeds more than the sum of lost demand and the units' leftover cost, stocking/hoarding behavior was elevated. Increase in interruption in supply and retail price leads to hoarding a quantity of the demand in the first time period to fulfill the demand in the second time period.

\subsection{Impact on percentage of customer satisfaction obtained in high-indexed retailers}

This study examines the impact of the two aforementioned models on the percentage of customer satisfaction obtained in high- and low-indexed retailers while increasing $\beta_{3,4}$ in the WOCSS and WCSS models. Figure 15 illustrates the effect of customer-segmented substitution on customer satisfaction. An interesting fact to notice here is that the hoarding behavior arises due to increase in the retail price. As mentioned in Section 4.2 .2 , to satisfy the demand from HIS, excess inventory is substituted in the first substitution phase, whereas both the excess inventory and the orders deallocated from LIS are used in the second phase of substitution. The third phase of substitution is that the demand of stores in the first time period is to hoard in order to satisfy the demand of HIS in the second time period. Because of rise in the retail price in the second time period, which exceeds more than the sum of lost demand and the units' leftover cost, stocking/hoarding behavior was elevated.

\subsection{Impact on percentage of overall customer satisfaction obtained in retailers}

Given the variation of the rate of interruption in supply for the $3 \mathrm{rd}$ and 4 th products ranging from 0 to 1 , its impact on the percentage of overall customer satisfaction

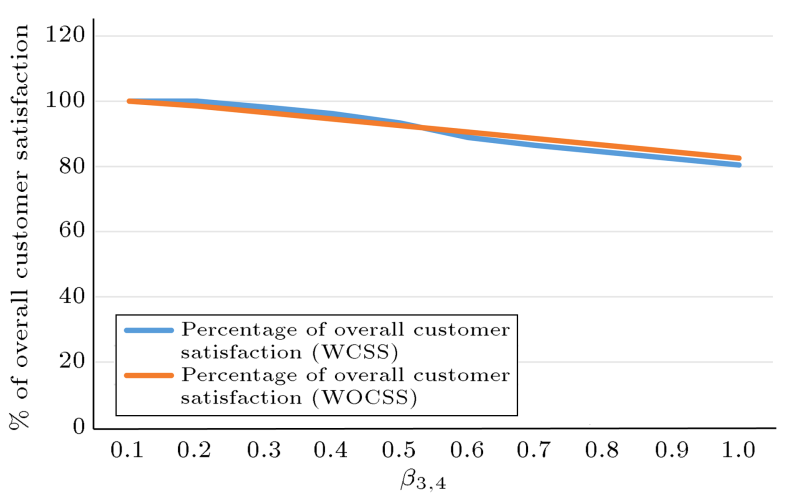

Figure 16. Impact on the overall percentage of customer satisfaction while increasing $\beta_{3,4}$ in the Without Customer Segmentation Substitution (WOCSS) and With Customer Segmentation Substitution (WCSS) models.

for retailers is investigated. Figure 16 shows that, as discussed in Section 4.2.3, when interruption in supply is 0.5 , the first phase of substitution takes place; when it is above 0.5 , the second and third phase substitutions take place, leading to a reduction in the overall satisfaction level of retailers in the WCSS model.

\subsection{Impact on inventory}

Herein, this study considers the rate of interruption in supply for the 3rd and 4th products ranging from 0 to 1 and investigates its impact on inventory. Figure 17 shows that there are three stages. In the initial stage (interruption in supply 0.1), substitution does not take place and the demand is satisfied by some percentages using initial inventory. In the second stage where interruption occurs in the supply rate from 0.2 to 0.6 for the WCSS model and from 0.2 to 0.4 for WOCSS model, the units' leftover is the same because the rates of panic are consistent; therefore, the maximum allowable order quantity to order in the first time period is attained where the rate of interruption in supply is 0.2 . In the third stage (interruption in supply above 0.6 for WCSS model and 0.4 for the WOCSS model, an increase in retail price and interruption in

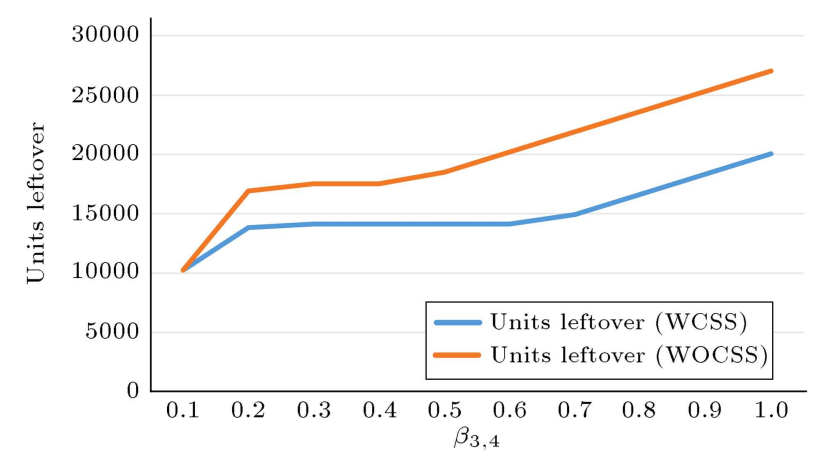

Figure 17. Impact on inventory while increasing $\beta_{3,4}$ in the Without Customer Segmentation Substitution (WOCSS) and With Customer Segmentation Substitution (WCSS) models. 
Table 9. Genetic Algorithm (GA) and CPLEX results for the example problem.

\begin{tabular}{cccccc}
\hline GA & CPLEX & $\begin{array}{c}\text { GAP }=((\text { CPLEX }- \text { GA) } \\
/ \text { CPLEX }) * \mathbf{1 0 0}\end{array}$ & $\begin{array}{c}\text { Run time(s) } \\
(\text { GA })\end{array}$ & $\begin{array}{c}\text { Run time(s) } \\
\text { (CPLEX) }\end{array}$ \\
\hline Profit & 946850 & 958656 & -1.23 & 45 & 0.3 \\
\hline
\end{tabular}

Table 10. Comparison of decisions in Genetic Algorithm (GA) and CPLEX results for the example problem.

\begin{tabular}{cccc}
\hline Product & GA & CPLEX & $\begin{array}{c}\text { GAP }=((\text { CPLEX - GA }) \\
\text { /CPLEX }) * \mathbf{1 0 0}\end{array}$ \\
\hline P1 in HIS & 8001 & 8001 & 0 \\
P2 in HIS & 7981 & 7981 & 0 \\
P3 in HIS & 7331 & 7331 & 0 \\
P4 in HIS & 6806 & 6806 & 0 \\
P1 in LIS & 639 & 2672 & -76.08533 \\
P2 in LIS & 2658 & 1645 & 61.5805 \\
P3 in LIS & 0 & 0 & 0 \\
P4 in LIS & 0 & 0 & 0 \\
TSQ & 1683 & 1842 & -8.63 \\
\hline
\end{tabular}

supply increases the hoarding behavior. The demand of the stores in the first time period is utilized to fulfill the demand in the second time period, which increases the inventory.

\section{Comparison of Genetic Algorithm (GA)}

Tables 9 and 10 show the performance of the mathematical model by comparing the profit, decision variables, and CPU runtime. The parameters of brand $\mathrm{G}$ from Tsao et al. [26] are used to solve the problem in the proposed GA. The population size is set to 75 and the elite preserving operation is set to $14 \%$ of population size. The crossover and mutation probabilities are 0.3 and 0.8 , respectively. Table 9 shows the total expected profit and CPU time (seconds) of the CPLEX model and the proposed GA. The GA terminates when the iteration reaches 1000 . Table 10 shows the comparison of the decision variable from the CPLEX and GA. $P_{k}$ in HIS represents the sum of product $k\left(P_{k}\right)$ received in HIS. $P_{k}$ in LIS represents the sum of product $k\left(P_{k}\right)$ received in LIS. Similarly, Total Substitution Quantity (TSQ) denotes the sum of substitution quantity received in all of the stores. In the first time period, there is no shortage and all the retailers are viewed as HIS. Hence, send quantity and the quantity received are equal to the demand. Hence, Table 10 shows the decision for the second time period.

\section{Conclusion}

This paper proposed the With Customer Segmentation Substitution (WCSS) model for the single-brand multi-weighted products in two different periods of panic buying. To ensure the wholesaler's maximum aggregate profit, this study investigated the optimum number of products substituted, order quantity, and unsatisfied and demand number of leftover units. This study varied substitution cost as a percentage of the product cost and examined the effects on wholesaler profits in the Without Customer Segmentation Substitution (WOCSS) and WCSS models. The objective of decision-makers is to maximize the total expected profit of the wholesaler. From a managerial point of view, obtained findings showed that substitution and customer segmentation increased profit significantly. The importance of segregating customers into highindexed and low-indexed was studied. Moreover, experimental analysis of the WCSS model showed that the High-Indexed Stores (HIS) customer satisfaction always outperformed the WOCSS model. Higher retail prices in the second time period provide an interesting finding whose hoarding behavior increases in the first time period. A comparison of the WCSS and WOCSS models clearly indicates that the WCSS model reduces inventory efficiently. In addition, the interruption in supply and rate of panic was modified to determine the effect of substitution and customer segmentation on wholesaler profit and customer satisfaction. Escalation of interruption in supply reduces the profit and customer satisfaction. While an increase in the rate of panic expands the inventory and improves profit and customer satisfaction if interruption in the supply occurs. Finally, the numerical example for the WCSS model was solved by Genetic Algorithm (GA) and the solution was compared with the obtained CPLEX solution. The proposed model can be extended by employing multi-product and multi-weight product substitution for further research.

\section{References}

1. Special Correspondent "Motorists resort to panic buying", October 2015, The Hindu (2015). http://www.thehindu.com/news/national/andhrapradesh/motorists-resort-to-panicbuying/article7710190.ece.1

2. "NOC dispatches fuel exceeding daily demand", The Himalayan Times, https://thehimalayan-times.com/ nepal/noc-dispatches-fuel-exceeding-daily-demand/ (2015).

3. Shou, B., Xiong. H., and Shen, Z.M. "Consumer panic buying and quota policy under interruption in supplys", working paper (2016). 
4. Fang, Y. and Shou, B. "Managing supply uncertainty under supply chain Cournot competition", European Journal of Operational Research, 243, pp. 156-176 (2015).

5. Kumar, M., Basu, P., and Avittathur, B. "Pricing and sourcing strategies for competing retailers in supply chains under disruption risk", European Journal of Operational Research, 265, pp. 533-543 (2018).

6. He, B., Huang, H., and Yuan, K. "The comparison of two procurement strategies in the presence of interruption in supply", Computers \& Industrial Engineering, 85, pp. 296-305 (2015).

7. Maclaughlin, S. "Japanese supermarket shelves are left completely empty as panic buying takes hold after deadly earthquake", Daily mail Online (2016). http://www.dailymail.co.uk/news/article-3545172 /Japanese-locals-panic-buy-supplies-shelves-leavingqueue-food-water-two-deadly-earthquakes-kill-41people.html. 18 April 2016.

8. Mardan, E., Sadegh Amalnick, M.. Rabbani, M., and Jolai, F. "A robust optimization approach for an inventory problem with emergency ordering and product substitution in an uncertain environment: A case study in pharmaceutical industry", Scientia Iranica, Transactions E: Industrial Engineering, 24, pp. 1533-1546 (2017).

9. Transchel, S. "Inventory management underpricebased and stock out based substitution", European Journal of Operational Research, 262, pp. 996-1008 (2017).

10. Rao, U.S., Swaminathan, J.M., and Zhang, J. "Multiproduct inventory planning with downward substitution, stochastic demand and setup costs", IIE Transactions, 36, pp. 59-71 (2004).

11. Netessine, S. and Rudi, N. "Centralized and competitive inventory models with demand substitution", Operations Research, 51(2), pp. 329-335 (2003).

12. Hoseininia, M., Seyed Esfahani, M.M., Didehvar, F., and Haghi, A. "Inventory competition in a multichannel distribution system: The Nash and Stackelberg game", Scientia Iranica, Transactions E: Industrial Engineering, 20, pp. 846-854 (2013).

13. Yücel, E., Karaesmen, F., Salman, F.S., and Türkay, M. "Optimizing product assortment under customerdriven demand substitution", European Journal of Operational Research, 199, pp. 759-768 (2009).

14. Stavrulaki, E. "Inventory decisions for substitutable products with stock-dependent demand", International Journal of Production Economics, 129, pp. 6578 (2011).

15. Vaagen, H., Wallace, S.W., and Kaut, M. "Modelling consumer-directed substitution", International Journal of Production Economics, 134, pp. 388-397 (2011).

16. Bayindir, Z.P., Erkip, N., and Gullu, R. "Assessing the benefits of remanufacturing option under one-way substitution and capacity constraint", Computers \& Operations Research, 34, pp. 487-514 (2007).

17. Kim, S.W. and Bell, P.C. "A note on the optimal pricing and production decisions with price-driven substitution", International Transactions in Operational Research, 22(6), pp. 1097-1116 (2015).

18. Pentico, D.W. "The assortment problem: A survey", European Journal of Operational Research, 190, pp. 295-309 (2008).

19. Lang, J.C. and Domschke, W. "Efficient reformulations for dynamic lot-sizing problems with product substitution", OR Spectrum, 32, pp. 263-291 (2010).

20. Yu, Y., Shou, B., Ni, Y., and Chen, L. "Optimal production, pricing, and substitution policies in continuous review production-inventory systems", European Journal of Operational Research, 260, pp. 631-649 (2016).

21. Xu, H., Yao, D.D., and Zheng, S. "Optimal policies for a two-product inventory system under a flexible substitution scheme", Production and Operations Management, 25(6), pp. 1088-1105 (2016).

22. Peebles, G. "Famine and government neglect in Ethiopia", Counterpunch, http://www.counterpunch. org/2016/01/08/famine-and-government-neglect-inEthiopia/ (2016).

23. Ervolina, T., Ettl, M., Lee, Y., and Peters, D. "Managing product availability in an assemble-toorder supply chain with multiple customer segments", OR Spectrum, 31(1), pp. 257-280 (2009).

24. Jua, W., Gabor, A.F., and van Ommeren, J.C.W. "An approximate policy for a dual-sourcing inventory model with positive lead times and binomial yield", European Journal of Operational Research, 244, pp. 490-497(2015).

25. Hsu, V.N., Li, C.-N., and Xiao, W "Dynamic lot size problems with one-way product substitution", IIE Transactions, 37, pp. 201-215 (2005).

26. Tsao, Y.-C. Praveen, V.R.P.R., and Yu, V. "Product substitution in different weights and brands considering customer segmentation and panic buying behavior", Industrial Marketing Management, 77, pp. 209220 (2019).

27. Yglesias, M. "The case for price gouging", URL http://www.slate.com/articles/business/moneybox/ 2012/10/sandy_price_gouging_anti_gouging_laws_make natural_disasters_worse.html (2012).

28. Dixit, A.K. and Pindyck, R.S., Investment under Uncertainty, Princeton University Press, Princeton, NJ (1994).

29. Li, C.L. and Kouvelis, P. "Flexible and risk-sharing supply contracts under price uncertainty", Management Science, 45(10), pp. 1378-1398 (1999).

\section{Biographies}

Yu-Chung Tsao is a Professor at the Department of Industrial Management at National Taiwan University 
of Science and Technology, Taipei, Taiwan. He was a visiting scholar in the School of Industrial and Systems Engineering at Georgia Institute of Technology. He received a $\mathrm{PhD}$ in Industrial Management from National Central University. He has published more than 100 research papers. His current research interests include supply chain and logistics management, production and operation management, decision sciences, business analysis, artificial intelligence application, operations marketing/financing interface integration, and revenue management.

Praveen Vijaya Raj Pushpa Raj is currently a PhD student at the Department of Industrial Management at National Taiwan University of Science and Technology, Taipei, Taiwan. His current interests in research are applied operations research and supply chain management. 